\title{
Dietary leucine supplementation alters energy metabolism and induces slow-to-fast transitions in longissimus dorsi muscle of weanling piglets
}

\author{
Qiwen Fan ${ }^{1,2,3}$, Baisheng Long ${ }^{1,2,3}$, Guokai Yan ${ }^{1,2,3}$, Zhichang Wang ${ }^{1,2,3}$, Min Shi ${ }^{1,2,3}$, Xiaoyu Bao ${ }^{1,2,3}$, \\ Jun $\mathrm{Hu}^{1,2,3}$, Xiuzhi $\mathrm{Li}^{1,2,3}$, Changqing Chen ${ }^{1,2,3}$, Zilong Zheng ${ }^{1,2,3}$ and Xianghua Yan ${ }^{1,2,3 *}$ \\ ${ }^{1}$ College of Animal Sciences and Technology, Huazhong Agricultural University, Wuhan, 430070 Hubei, \\ People's Republic of China \\ ${ }^{2}$ The Cooperative Innovation Center for Sustainable Pig Production, Wuban, 430070 Hubei, People's Republic of China \\ ${ }^{3}$ Hubei Provincial Engineering Laboratory for Pig Precision Feeding and Feed Safety Technology, Wuban, 430070 Hubei, \\ People's Republic of China
}

(Submitted 14 December 2016 - Final revision received 28 April 2017 - Accepted 3 May 2017)

\section{Abstract}

Leucine plays an important role in promoting muscle protein synthesis and muscle remodelling. However, what percentage of leucine is appropriate in creep feed and what proteome profile alterations are caused by dietary leucine in the skeletal muscle of piglets remain elusive. In this case, we applied isobaric tags for relative and absolute quantitation to analyse the proteome profile of the longissimus dorsi muscles of weanling piglets fed a normal leucine diet (NL; $1.66 \%$ leucine) and a high-leucine diet (HL; $2 \cdot 1 \%$ leucine). We identified 157 differentially expressed proteins between these two groups. Bioinformatics analysis of these proteins exhibited the suppression of oxidative phosphorylation and fatty acid $\beta$-oxidation, as well as the activation of glycolysis, in the HL group. For further confirmation, we identified that SDHB, ATP5F1, ACADM and HADHB were significantly down-regulated $(P<0 \cdot 01$, except ATP5F1, $P<0 \cdot 05)$, whereas the glycolytic enzyme pyruvate kinase was significantly up-regulated $(P<0.05)$ in the HL group. We also show that enhanced muscle protein synthesis and the transition from slow-to-fast fibres are altered by leucine. Together, these results indicate that leucine may alter energy metabolism and promote slow-to-fast transitions in the skeletal muscle of weanling piglets.

Key words: Leucine: Skeletal muscles: Energy metabolism: Slow-to-fast transitions: Weanling piglets

Branched chain amino acids, particularly leucine, are the proteogenic amino acids involved in the regulation of animal physiology ${ }^{(1)}$. In addition to serving as a substrate for protein synthesis, leucine is also involved in several cellular processes, such as protein synthesis, energy metabolism and tissue regeneration. Several studies have indicated that leucine can regulate the mitochondrial biogenesis of skeletal muscle ${ }^{(2,3)}$, glucose uptake $^{(4-6)}$ and fatty acid oxidation ${ }^{(7,8)}$.

The skeletal muscle is an adaptive tissue involved in energy metabolism and protein turnover, and the main fibre types can be determined by the myosin heavy chain (MyHC) isoform expressed, namely, slow-oxidative type I (MyHC I), fastoxidative type IIa (MyHC IIa), intermediate type IIx (MyHC IIx) and fast-glycolytic type IIb (MyHC IIb) ${ }^{(9,10)}$. Most muscles in mammals contain a mixture of fibre types, and the fibre phenotype demonstrates high plasticity because of the diverse components of muscle fibres that are susceptible to the changes in nutrition, physical activity and environmental conditions ${ }^{(11,12)}$. Furthermore, skeletal muscles are of critical importance as storage organs for energy and as materials for maintenance of the immune system and many metabolic pathways ${ }^{(13,14)}$ under the condition of weaning stress.

Previous studies have shown that leucine stimulates protein synthesis in skeletal muscles through mechanistic targeting of the rapamycin (mTOR) pathway in rats ${ }^{(15-17)}$, neonatal pigs $^{(18-20)}$ and humans ${ }^{(21-23)}$, whereas the increased rate of protein synthesis caused by high-leucine levels does not necessarily lead to lean mass or body mass accretion. Moreover, several studies have shown that undernutrition decreases fibre size ${ }^{(24)}$ and has more an important impact on type II fibres than on other types ${ }^{(25,26)}$. In addition, Xia et $a l{ }^{(27)}$ reported dietary supplementation with leucine combined with moderate aerobic

Abbreviations: AMPK, AMP-activated protein kinase; FAO, fatty acid $\beta$-oxidation; HL, high-leucine diet; iTRAQ, isobaric tags for relative and absolute quantitation; LD, longissimus dorsi; MSTN, myostatin; mTOR, mechanistic target of rapamycin; MyHC, myosin heavy chain; NL, normal leucine diet; OXPHOS, oxidative phosphorylation; PGC-1, PPAR $\gamma$ coactivator-1; SDH, succinate dehydrogenase; TNNI, troponin I protein.

* Corresponding author: X. Yan, fax +86 27 87280408, email xhyan@mail.hzau.edu.cn 
training effectively increases fast-twitch muscle fibres. However, the proteome profile alterations caused by dietary leucine in the skeletal muscle of piglets remains elusive.

Proteomic analysis has been used to determine the markers of fibre-type specification ${ }^{(28-30)}$, the metabolic processes in muscle development ${ }^{(31,32)}$, the effect of exercise, weight loss ${ }^{(33,34)}$ and the pathological effects of type 2 diabetes and ageing-related changes on skeletal muscle ${ }^{(35-37)}$. In addition, Wang et al. ${ }^{(38)}$ reported that $\mathrm{ZnO}$ supplementation improves the redox state and prevents apoptosis in the jejunum of weanling piglets using two-dimensional gel electrophoresis and MS. Goichon et $a l .{ }^{(39)}$ revealed that leucine supplementation may slow down fatty acid $\beta$-oxidation (FAO) in human duodenal mucosa using the same methods. Thus, this study was designed to investigate the alterations of differentially expressed proteins and their metabolic pathways, regulated by leucine, in the skeletal muscle of weanling piglets.

\section{Methods}

\section{Animals and diets}

All procedures on animals and all the experiments were conducted in accordance with the ethical guidelines for animal research established and approved by the Institutional Animal Care and Use Committee at Huazhong Agricultural University. A total of forty-eight male piglets (Yorkshire $\times$ Large White, weaned at $21 \mathrm{~d}$ of age) were housed in six pens of eight piglets each, with the pens having slotted stainless steel floors, and assigned randomly to one of two dietary groups (three pens per group). The control group was fed the basal diet containing $1.66 \%$ leucine (normal leucine level (NL)). The treatment group was fed the basal diet supplemented with leucine to provide $2 \cdot 1 \%$ leucine (high-leucine diet (HL)). The temperature was kept at $25-28^{\circ} \mathrm{C}$ day-night. Each pen was equipped with a feeder and a nipple waterer to allow all piglets free access to feed and water. Growth performance of the weanling piglets in the NL and the HL groups are shown in the online Supplementary Table S1. One piglet per pen was slaughtered to collect longissimus dorsi (LD) muscle samples at $35 \mathrm{~d}$ of age after weaning. Muscle samples were placed in liquid $\mathrm{N}_{2}$ and stored at $-80^{\circ} \mathrm{C}$.

\section{Reagents}

The following antibodies were used: antibodies to mediumchain-specific acyl-CoA dehydrogenase (ACADM) (A1873), ATP synthase subunit b (ATP5F1) (A7645), glutathione S-transferase pi 1(GSTP1) (A5691), long-chain 3-ketoacyl-CoA thiolase (HADHB) (A5716), dual specificity mitogen-activated protein kinase kinase 6 (MAP2K6) (A2575), MyHC IIx (A6935), MyHC IIa (A3620), MyHC I (A7564), 40S ribosomal protein S4, X isoform (RPS4X) (A6730), troponin I protein (TNNI) 1 (A4161), TNNI2 (A7937) and $\alpha$-tubulin (AC007) from ABclonal; antibodies to AMP-activated protein kinase (AMPK) (sc-74461) and p-AMPK (Thr172, sc-33524) from Santa Cruz Biotechnology; antibodies to myostatin (MSTN) (D160418), PPAR $\gamma$ coactivator$1 \alpha$ (PGC-1 $\alpha$ ) (D162041), pyruvate kinase (PKM) (D120008) and succinate dehydrogenase (SDH) B (D162175) from BBI Life
Sciences; antibodies to mTOR (2983), p-mTOR (Ser2448, 2971), p $70^{\mathrm{s} 6 \mathrm{~K}}(2708)$ and $\mathrm{p}-\mathrm{p} 70^{\mathrm{S} 6 \mathrm{~K}}$ (Thr389, 9234) from Cell Signaling Technology; antibodies to MyHC IIb (20140-1-AP), PGC-1 $\beta$ (22378-1-AP) from Protein Tech Group; HRP-conjugated antimouse secondary antibody from Cell Signaling Technology; and anti-rabbit secondary antibody from Sigma.

Protein sample preparation, digestion and isobaric tags for relative and absolute quantitation labelling

Muscle samples were ground into a powder in liquid $\mathrm{N}_{2} ; 150 \mathrm{mg}$ powder was extracted with $1 \mathrm{ml}$ lysis buffer $(7 \mathrm{M}$ urea, $2 \mathrm{M}$ thiourea, $4 \%$ 3-[(3-cholamido-propyl)-dimethylammonio]1-propanesulfonate (CHAPS), $40 \mathrm{~mm}$ TRIS-HCl, pH 8.5, $10 \mathrm{~mm}$ dithiothreitol containing 1\% protease inhibitor cocktail (P8340; Sigma) on ice surface, fully homogenised and then centrifuged at $4^{\circ} \mathrm{C}, 12000 \mathrm{~g}$ for $15 \mathrm{~min}$. The supernatants were collected to new clean tips and the protein concentration was quantified using the Bradford method. To reduce the effect of variation in biological samples on the proteomic analysis, three muscle samples from each group were pooled together and stored at $80^{\circ} \mathrm{C}$. These mixed protein samples were used for isobaric tags for relative and absolute quantitation (iTRAQ) and Western blotting assays.

A total of $100 \mathrm{mg}$ mixed protein from each group was digested with Trypsin Gold (Promega) with the weight ratio of protein:trypsin $=30: 1$ at $37^{\circ} \mathrm{C}$ for $16 \mathrm{~h}$. Then, the digested peptides were vacuum centrifuged for drying, reconstituted in $0.5 \mathrm{M}$ tetraethylammonium bromide (Applied Biosystems) and labelled according to the manufacture's protocol for 8-plex iTRAQ reagent (Applied Biosystems) as follows: the NL sample was labelled with 119-tag and 121-tag. The peptides were labelled with the isobaric tags and incubated at room temperature for $2 \mathrm{~h}$. The labelled peptide were then pooled and dried using vacuum centrifugation.

\section{Strong Cation Exchange fractionation and liquid chromatography-electrospray ionisation-MS/MS analysis}

Labelled peptides were separated by Strong Cation Exchange (SCX) chromatography using LC-20AB HPLC Pump system (Shimadzu). The dried peptide mixture was reconstituted with $4 \mathrm{ml}$ buffer A (25 mm $\mathrm{NaH}_{2} \mathrm{PO}_{4}$ in $25 \%$ acetonitrile (ACN), pH $2 \cdot 7)$ and gradient eluted with buffer $\mathrm{B}\left(25 \mathrm{~mm} \mathrm{NaH}_{2} \mathrm{PO}_{4}, 1 \mathrm{M} \mathrm{KCl}\right.$ in $25 \% \mathrm{ACN}, \mathrm{pH} 2 \cdot 7)$. Peptides were loaded onto a $4.6 \times 250 \mathrm{~mm}$ Ultremex SCX column (Phenomenex) with the following elution procedure: flow rate, $1 \mathrm{ml} / \mathrm{min}$; buffer A for $10 \mathrm{~min}$; buffer B, 5-60\% for $27 \mathrm{~min}, 60-100 \%$ for $1 \mathrm{~min}$. Elution was monitored by measuring the absorbance at $214 \mathrm{~nm}$. A total of twenty fractions were collected and desalted with a Strata X C18 column (Phenomenex).

Each fraction was dried and resuspended in buffer A ( $2 \% \mathrm{ACN}, 0 \cdot 1 \%$ formic acid) for LC-MS/MS. On average, the final concentration of peptides was about $0.5 \mu \mathrm{g} / \mu \mathrm{l}$, following which $10 \mu \mathrm{l}$ of each fraction was loaded on a LC-20AD nanoHPLC (Shimadzu) using a 2-cm C18 trap column. Later, the peptides were eluted onto a $10-\mathrm{cm}$ analytical $\mathrm{C} 18$ column (inner diameter $75 \mu \mathrm{m}$ ) using the following procedure: loading 
$8 \mu \mathrm{l} / \mathrm{min}$ for $4 \mathrm{~min}$, then subjecting to a gradient of $2-35 \%$ in buffer B (98\% ACN, 0.1\% formic acid) at $300 \mathrm{nl} / \mathrm{min}$ for $44 \mathrm{~min}$, followed by $2 \mathrm{~min}$ linear gradient to $80 \%$ and maintenance at $80 \%$ in buffer B for $4 \mathrm{~min}$, and finally returning to $5 \%$ in $1 \mathrm{~min}$. Next, all peptides were identified using tandem MS (MS/MS) in QEXACTIVE (Thermo Fisher Scientific) coupled online to the HPLC. Intact peptides were detected using Orbitrap (Thermo Fisher Scientific) at a resolution of 70000 and MS scans were obtained from 350 to $2000 \mathrm{~m} / z$. A total of fifteen precursor ions were selected using high-energy collision dissociation with a dynamic exclusion duration of $15 \mathrm{~s}$. The MS/MS scan range was $100-1800 \mathrm{~m} / \mathrm{z}$.

\section{Data analysis}

Protein identification was performed using Mascot search engine (version 2.3.02, Matrix Science) embedded into Proteome Discoverer 1.2 against the Uniport database containing pig protein sequences. For protein identification, a mass tolerance of 20 parts per million was permitted for intact peptide masses and $0 \cdot 1 \mathrm{Da}$ was permitted for fragmented ions. To minimise false-positive results, we counted only peptides at the $95 \% \mathrm{CI}$ and a false discovery rate $\leq 0 \cdot 01$, containing at least one unique peptide. For protein quantitation, a differentially expressed protein containing at least two unique spectra was used with a fold-change value $>1.2$ or $<0.83(1 / 1.2)$ with $P<0.05$ between the NL and the HL groups. Protein subcellular localisation prediction was on the basis of Gene Ontology (GO) annotation. The corresponding pathways that the proteins mapped were searched using online Kyoto Encyclopedia of Genes and Genomes (KEGG) database. The functional classification, network analysis and pathway analysis of differentially expressed proteins were analysed by core analysis using Ingenuity Pathway Analysis (IPA) software.

\section{Western blotting analysis}

Tissue lysates were mixed with the $5 \times$ protein loading buffer (161-0737; Bio-Rad). After heat denaturation, equal amounts $(15 \mu \mathrm{g})$ of cellular proteins were separated using SDS-PAGE, followed by electrotransfer onto a polyvinylidene fluoride (PVDF) membrane (162-0177; Bio-Rad). After blocking with 5\% non-fat milk, the PVDF membrane was performed by incubation with primary antibodies (1:2000 dilution), then with secondary antibodies (1:10000 dilution), washing after each step with TBST (Tris-buffered saline, $0 \cdot 1 \%$ Tween 20) three times for $5 \mathrm{~min}$. Washing was carried out with TBS two times for 5 min before detection with Immobilon Western Chemiluminescent HRP substrate (no. WBKLS0500; Millipore).

\section{ATP and AMP assay}

The ATP and AMP levels in the skeletal muscle were determined by HPLC analysis. A quantity of $100 \mathrm{mg}$ muscle powder was extracted with $1 \mathrm{ml} 7 \%(\mathrm{w} / \mathrm{v}) \mathrm{HClO}_{4}$ on an ice surface. After centrifugation at $15000 \boldsymbol{g}$ for $10 \mathrm{~min}$ at $4^{\circ} \mathrm{C}$, the supernatant was removed and mixed with an equal volume of $1.03 \mathrm{M}$ $\mathrm{KOH}$, which was centrifuged again at $15000 \mathrm{~g}$ for $10 \mathrm{~min}$ at $4^{\circ} \mathrm{C}$; $20 \mu \mathrm{l}$ of supernatant was loaded on a LC-20AT HPLC
(Shimadzu) by an analytical column $(250 \mathrm{~mm} \times 4.6 \mathrm{~mm}$, internal diameter, $5 \mu \mathrm{m}$; Hypersil ODS2; Elite). The UV detector is set at $259 \mathrm{~nm}$.

\section{Statistical analysis}

All statistical analyses were carried out with GraphPad Prism 5.01.336 (GraphPad Software). The paired $t$ test was used for statistical analysis between two groups. The measurements were expressed as means with their standard errors. The significance level was set at $P<0.05$; * $P<0.05$; ** $P<0.01$; **** $P<0.001$.

\section{Results}

\section{Quantitative proteomic analysis of skeletal muscle after} leucine supplementation

To assess the differences in skeletal muscle proteome altered by leucine level, we analysed the LD muscle samples derived from the NL and the HL groups in which iTRAQ tags were applied (NL: 119 and HL: 121) (Fig. 1(a)). In this case, we showed that 157 quantifiable proteins were significantly altered by leucine supplementation, containing sixty-one up-regulated (fold change $>1.2$ with $P<0.05$ ) and ninety-six down-regulated (fold change $<0.83$ with $P<0.05$ ) proteins (Fig. 1(b) and online Supplementary Table S2). Heat map in different colours was used to show the differentially expressed protein profiles between the NL and the HL groups, and all the differentially expressed proteins are shown in Fig. 1(c).

\section{Functional classification, subcellular localisation and network analysis for differentially expressed proteins}

To unambiguously analyse the molecular functions of each of these differentially expressed proteins, we used the IPA software to get the functional classification. Fig. 2(a-c) shows the distribution charts of diseases and disorders, molecular and cellular function, and the physiological system development and function. (A complete catalogue of each part is exhibited in the online Supplementary Table S3). We predicted that these significantly altered proteins may be involved in enhanced processes, such as skeletal and muscular disorders (Fig. 2(a)), energy production, lipid metabolism and protein synthesis (Fig. 2(b)), cell morphology, organ morphology and skeletal and muscular system development and function (Fig. 2(c)).

To assess the organelle specificity of the differentially expressed proteins, we analysed the subcellular localisation according to their GO annotation. All categories were ranked by the numbers of differentially expressed proteins. These results showed that the cytoplasm, mitochondrion, membrane and the nucleus were enriched with both up-regulated proteins and down-regulated proteins (Fig. 2(d)).

In the next step, we analysed the interaction network of the 157 differentially expressed proteins (online Supplementary Table S4). Proteins were enriched in two networks, predominantly, 'energy production, lipid metabolism, small molecule biochemistry' and 'protein synthesis, energy production, nucleic acid metabolism' (Fig. 2(e)). 
(a)

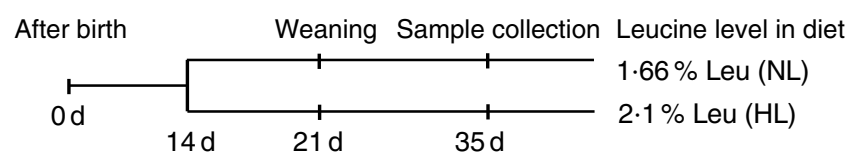

(b)

\begin{tabular}{|c|c|c|}
\hline & Up-regulated & Down-regulated \\
\hline $\begin{array}{c}\text { Protein } \\
\text { numbers }\end{array}$ & 61 & 96 \\
\hline
\end{tabular}

(c)

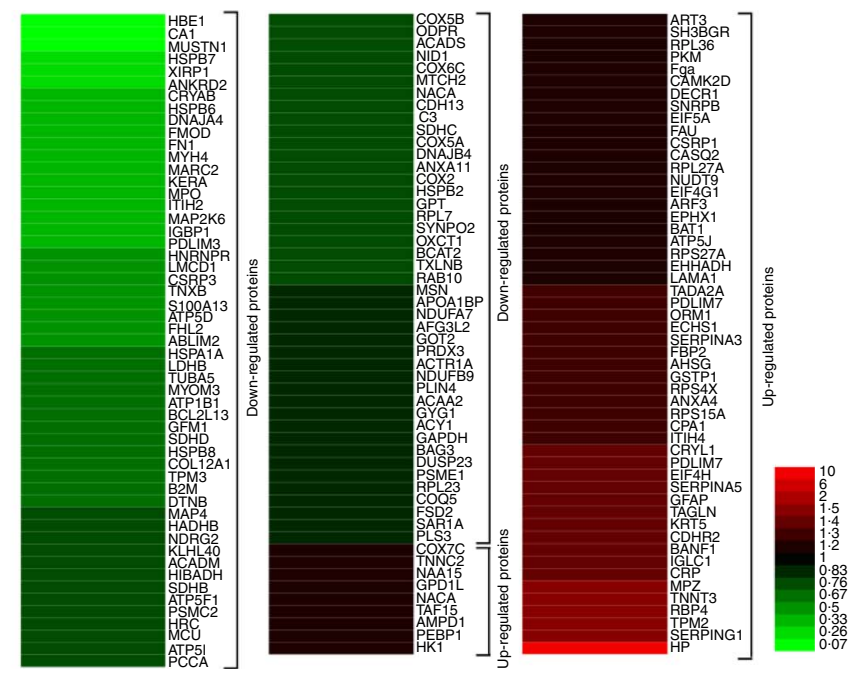

Bioinformatics analysis

$\mathrm{HL}(2 \cdot 1 \%)$

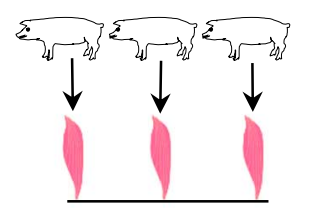

Pooled
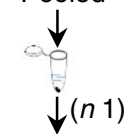

and label

ucine supplementation alters energy metabolism in muscle tissue

To gain a biological insight into differentially expressed proteins, we analysed the canonical pathways using IPA (online Supplementary Table S5). The top canonical pathways were ranked by $P$ value (Fig. 3(a)) and the proteins enriched in each pathway were presented (Fig. 3(b)). The study results indicated that many energy production pathways were enriched. The oxidative phosphorylation (OXPHOS) pathway showed a minimum $P$ value (Fig. 3(a)) and a total of fourteen proteins (ATP synthase subunit delta (ATP5D), ATP synthase subunit b (ATP5F1), ATP synthase subunit e (ATP5I), ATP synthase-coupling factor 6 (ATP5J), cytochrome c oxidase subunit $5 \mathrm{~A}$ (COX5A), cytochrome c oxidase subunit $5 \mathrm{~B}$ (COX5B), cytochrome c oxidase subunit 6C (COX6C), cytochrome c oxidase subunit $7 \mathrm{C}(\mathrm{COX} 7 \mathrm{C})$, cytochrome c oxidase subunit 2 (MT-CO2), NADH dehydrogenase [ubiquinone] 1 alpha subcomplex subunit 7 (NDUFA7), NADH dehydrogenase [ubiquinone] 1 beta subcomplex subunit 9 (NDUFB9), succinate dehydrogenase [ubiquinone] iron-sulfur subunit (SDHB), succinate dehydrogenase cytochrome b560 subunit (SDHC), succinate dehydrogenase [ubiquinone] cytochrome b small subunit (SDHD)) were identified as the members of this pathway. Notably, twelve of fourteen identified proteins were down-regulated in the HL group (Table 1), which suggests that the OXPHOS pathway is suppressed by leucine supplementation. We further detected SDHB (0.761-fold in iTRAQ) and ATP5F1 (0.763-fold), the enzymes that participated in the OXPHOS pathway ${ }^{(40)}$, which were significantly decreased in the HL group $(P<0.05)$ (Fig. 3(c) and (d)). However, the study data also showed an increase in the expression of PKM (1.269-fold) in the glycolysis pathway in the iTRAQ experiment (Table 1) and immunoblotting analysis in the HL group (Fig. 3(e)). However, three of five quantified proteins in the FAO pathway were decreased in response to leucine supplementation (Table 1). HADHB (0.754-fold) and ACADM (0.759-fold) are two key proteins in FAO, and showed a decline in the HL group (Fig. 3(f) and (g)). Moreover, we showed that ATP concentration was significantly decreased in the leucine-supplemented group $(P<0.05)$ (Table 2$)$. Overall, these results suggest that dietary supplementation with leucine suppressed OXPHOS and FAO pathways, and up-regulated the glycolysis pathway in the LD muscle of weanling piglets.

\section{Leucine supplementation promotes protein synthesis and alters the constitution of muscle fibres}

The iTRAQ data showed a low $P$ value for the eukaryotic initiation factor 2 (EIF2) and the mTOR signalling pathways (Fig. 4(a) and online Supplementary Table S5). Among the nine 

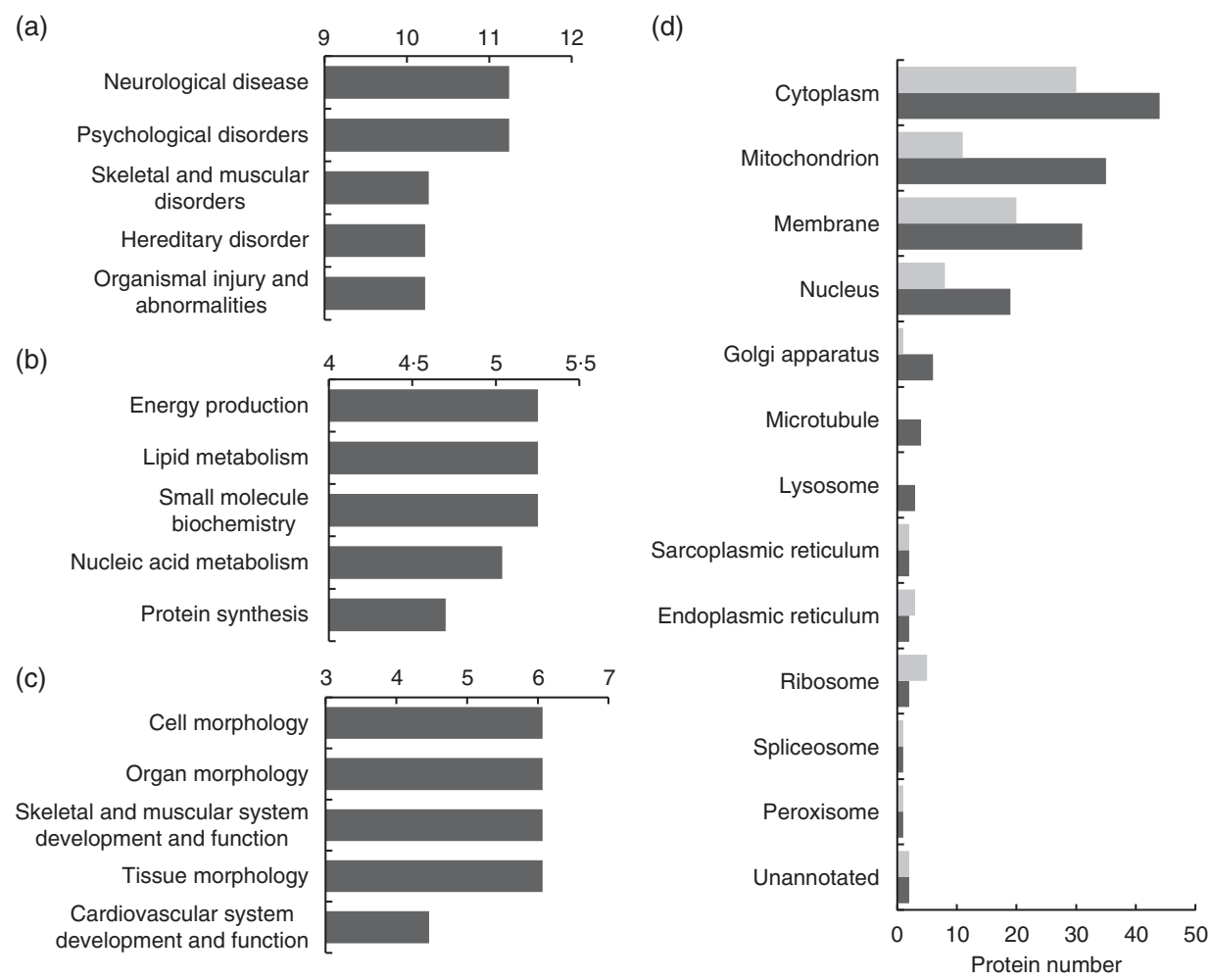

(e)

\begin{tabular}{clcc}
\hline Id & Top diseases and functions & Score & $\begin{array}{c}\text { Focus } \\
\text { molecules }\end{array}$ \\
\hline 1 & Energy production, lipid metabolism, small molecule biochemistry & 50 & 25 \\
2 & Protein synthesis, energy production, nucleic acid metabolism & 47 & 24 \\
3 & Cancer, hereditary disorder, organismal injury and abnormalities, reproductive & 41 & 22 \\
& system disease & & \\
4 & Development disorder, skeletal and muscular disorder, cardiovascular system & 40 & 21 \\
& development and function & 34 & 20 \\
5 & Cellular compromise, tissue development, cancer & 30 & 17 \\
6 & Haematological disease, hereditary disorder, metabolic disease & 23 & 15 \\
7 & Infectious disease, cell-to-cell signalling and interaction, inflammatory disease \\
8 & Organ morphology, organismal development, skeletal and muscular system & 19 & 12 \\
& development and function & & \\
\hline
\end{tabular}

Fig. 2. Functional analysis, subcellular localisation and key network analysis for differentially expressed proteins in high-leucine diet group compared with normal leucine diet group. The items of diseases and disorders (a), molecular and cellular functions (b) and physiological system development and function (c) categories were listed by $P$ value $(\square,-\log P$ ). (d) Subcellular localisation of the up-regulated proteins $(\square)$ and down-regulated proteins $(\square)$ for differentially expressed protein. (e) The top diseases and function networks about the differentially expressed proteins caused by leucine supplementation.

identified differentially expressed proteins in EIF2 signalling, seven proteins (eukaryotic translation initiation factor 4 gamma 1 (EIF4G1), 60S ribosomal protein L36 (RPL36), 60S ribosomal protein L27A (RPL27A), 40S ribosomal protein S30 (FAU), 40S ribosomal protein S15A (RPS15A), 40S ribosomal protein S27A (RPS27A), 40S ribosomal protein S4, X isoform (RPS4X)) were significantly up-regulated in the HL group (Table 1). We observed that the expression of RPS $4 \mathrm{X}$ and the ratio of p-mTOR:mTOR and $\mathrm{p}-\mathrm{p} 70^{\mathrm{S} 6 \mathrm{~K}}: \mathrm{p} 70^{\mathrm{S} 6 \mathrm{~K}}$ were increased in the HL group (Fig. $4(\mathrm{a}-\mathrm{c})$ ). These results indicated that leucine supplementation promoted protein synthesis in the skeletal muscle tissue.

Furthermore, we identified eight myofibrillar proteins in the iTRAQ data (Fig. 4(d)). These are mainly due to the differences in the muscle fibre types. TNNI1 and TNNI2 have been used as model genes to study the mechanisms of slow and fast fibrespecific expression. The data from the present study show that these two proteins have the ratio changed between HL and NL but with no significance. We tested the decreased expression of TNNI1 and increased expression of TNNI2 by Western blotting analysis after leucine supplementation (Fig. 4(e) and (f)). We also detected the content of four myosin proteins, MyHC I, MyHC IIa and MyHC IIx were significantly decreased, whereas MyHC IIb was increased in the HL group (Fig. $4(\mathrm{~g}-\mathrm{j})$ ). All these results reflect a possible modulation of slow-to-fast transitions.

\section{Leucine supplementation decreases the activity of $A M P$-activated protein kinase and suppresses the p38/c-JUN NH2-terminal protein kinase pathway}

We next examined PGC- $1 \alpha$ and PGC- $1 \beta$, the two key regulators for muscle fibre transitions, to explore how leucine is involved 
(a)

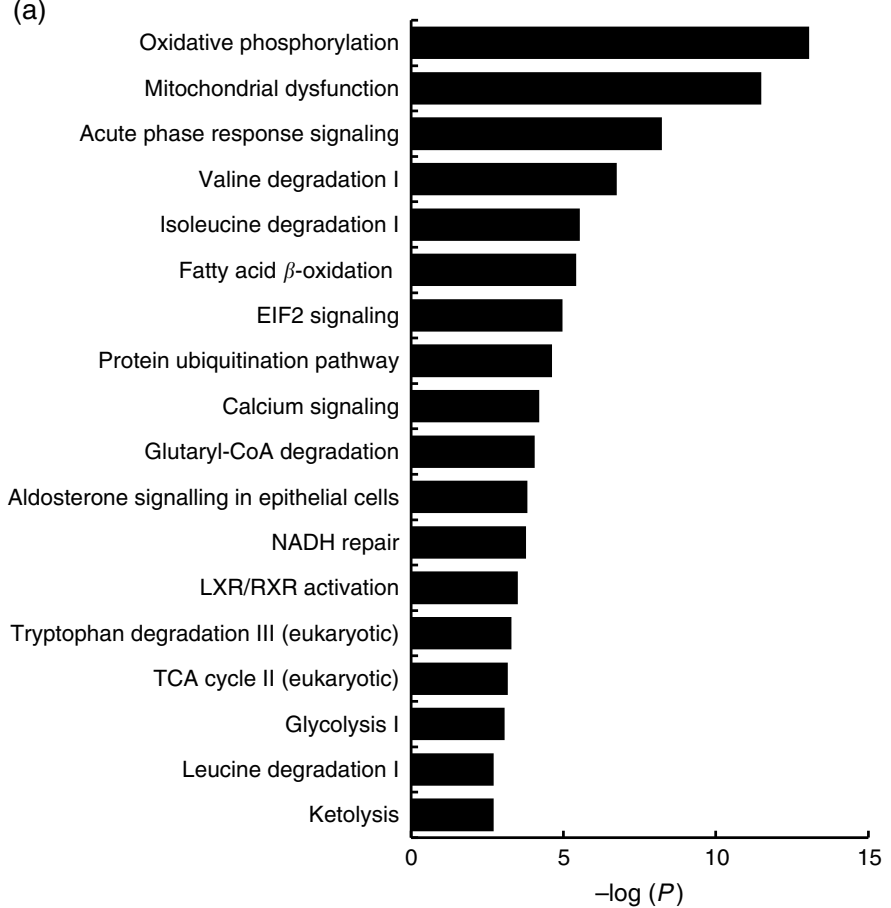

(c)

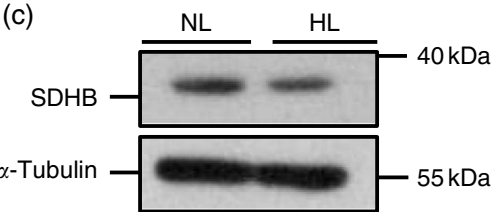

(d)
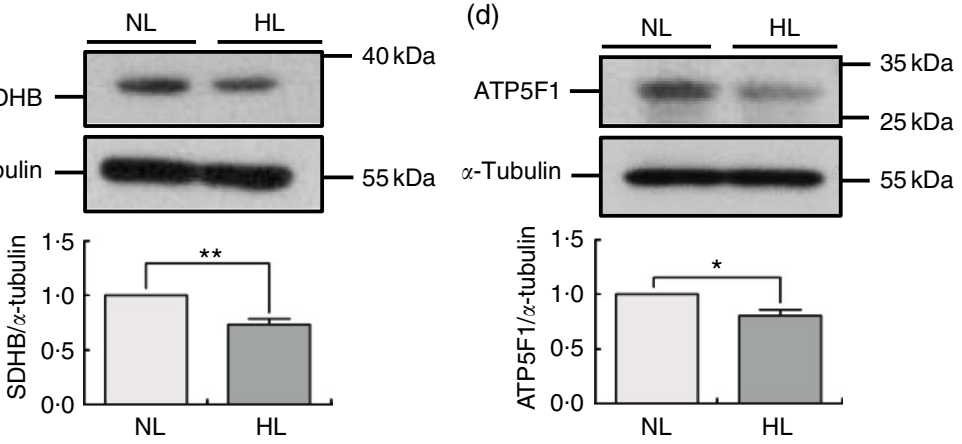

(f)
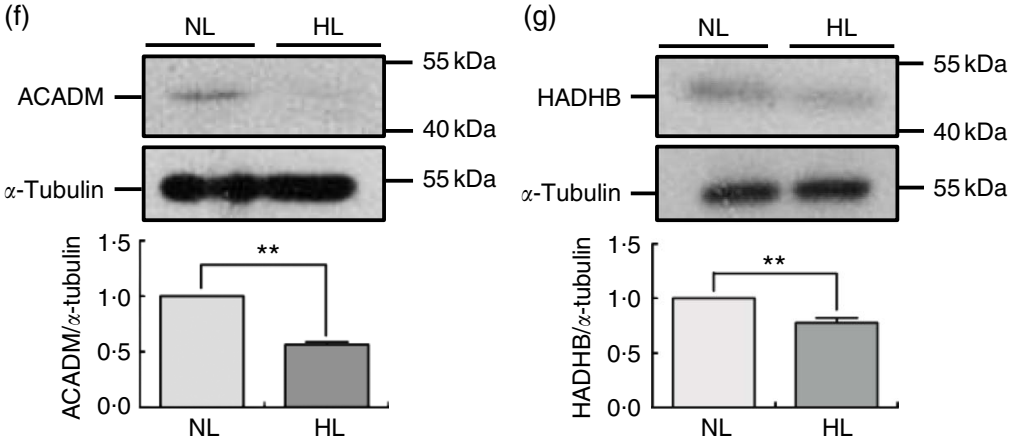

(b)

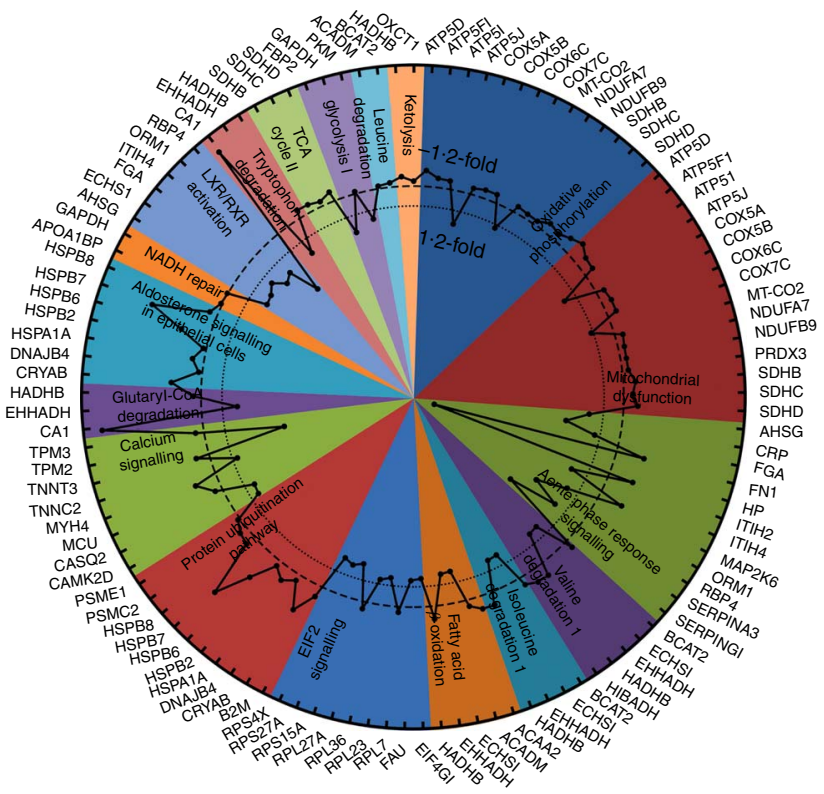

(e)
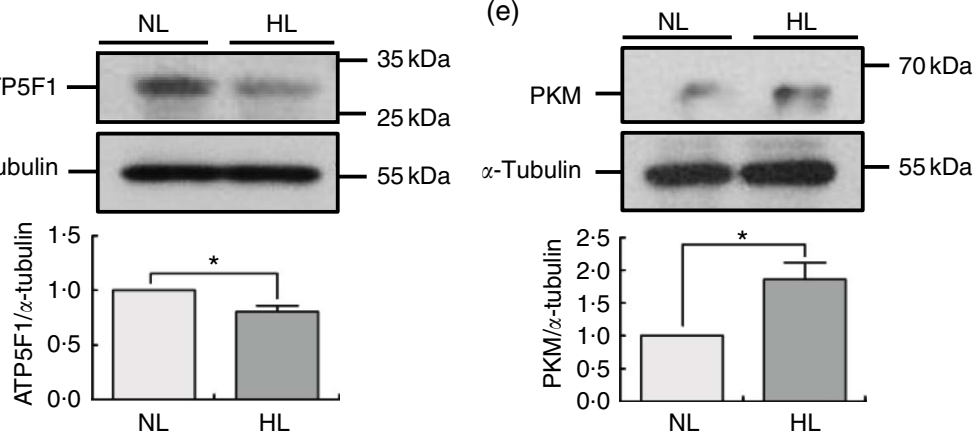

Fig. 3. Oxidative phosphorylation pathway and fatty acid $\beta$-oxidation pathway are suppressed, and glycolysis pathway is activated by leucine in skeletal muscle of

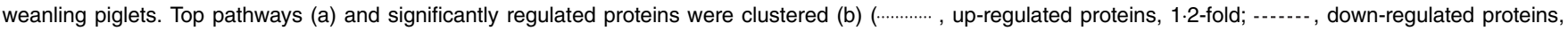
$-1 \cdot 2$-fold) in each pathway in response to leucine. The expression of SDHB (c), ATP5F1 (d), PKM (e) and ACADM (f), HADHB (g) in two groups were detected by Western blotting analysis. Values are means ( $n 5$ experiments) with their standard errors represented by vertical bars. ${ }^{*} P<0.05 ;{ }^{*} P<0.01$. $a$-Tubulin was detected as a loading control. HL, high-leucine diet; NL, normal leucine diet.

in muscle fibre transitions. PGC- $1 \alpha$ showed no significant change (Fig. 5(a)), but PGC-1 $\beta$ was down-regulated in the HL group (Fig. 5(b)). AMPK, as the main sensor of intracellular energy status, is activated by an increase in the AMP:ATP ratio $^{(41)}$. In the assay, the ratio of AMP:ATP and p-AMPK:AMPK are all decreased in the HL group (Fig. 5(c) and Table 2). These results suggest the inhibition of the activation of AMPK in leucine-supplemented piglets.

The study data also identified MAP2K6 (also named as MKK6, 0.646-fold) and GSTP1 (1.443-fold) with significant changes in 
Table 1. List of candidate proteins and pathways in response to leucine supplementation

\begin{tabular}{|c|c|c|c|c|}
\hline Pathways & Genes & Description & $\begin{array}{l}\text { Unique } \\
\text { peptide }\end{array}$ & $\begin{array}{l}\text { Fold change } \\
\text { (HL:NL) }\end{array}$ \\
\hline \multicolumn{5}{|c|}{ Oxidative phosphorylation } \\
\hline & ATP5D & ATP synthase subunit $\delta$, mitochondrial & 1 & $0.693^{*}$ \\
\hline & ATP5F1 & ATP synthase subunit $b$, mitochondrial & 2 & $0.763^{*}$ \\
\hline & ATP5I & ATP synthase subunit e, mitochondrial & 4 & $0.773^{\star}$ \\
\hline & ATP5J & ATP synthase-coupling factor 6 , mitochondrial & 6 & $1.372^{\star}$ \\
\hline & COX5A & Cytochrome $c$ oxidase subunit $5 \mathrm{~A}$, mitochondrial & 4 & $0.796^{\star}$ \\
\hline & COX5B & Cytochrome $\mathrm{c}$ oxidase subunit $5 \mathrm{~B}$, mitochondrial & 4 & $0.775^{\star}$ \\
\hline & COX6C & Cytochrome $\mathrm{c}$ oxidase subunit $6 \mathrm{C}$, mitochondrial & 5 & $0.779^{*}$ \\
\hline & $\operatorname{cox} 7 \mathrm{C}$ & Cytochrome $\mathrm{c}$ oxidase subunit $7 \mathrm{C}$, mitochondrial & 1 & $1 \cdot 201^{*}$ \\
\hline & MT-CO2 & Cytochrome $\mathrm{c}$ oxidase subunit 2 & 2 & $0.799^{\star}$ \\
\hline & NDUFA7 & $\begin{array}{l}\text { NADH dehydrogenase (ubiquinone) } 1 \text { a subcomplex } \\
\text { subunit } 7\end{array}$ & 1 & $0.82^{*}$ \\
\hline & NDUFB9 & $\begin{array}{l}\text { NADH dehydrogenase (ubiquinone) } 1 \beta \text { subcomplex } \\
\text { subunit } 9\end{array}$ & 2 & $0.825^{\star}$ \\
\hline & $S D H B$ & $\begin{array}{l}\text { Succinate dehydrogenase (ubiquinone) iron-sulphur } \\
\text { subunit, mitochondrial }\end{array}$ & 8 & $0.761^{*}$ \\
\hline & $S D H C$ & $\begin{array}{l}\text { Succinate dehydrogenase cytochrome b560 subunit, } \\
\text { mitochondrial }\end{array}$ & 1 & $0.793^{*}$ \\
\hline & $S D H D$ & $\begin{array}{l}\text { Succinate dehydrogenase (ubiquinone) cytochrome b } \\
\text { small subunit, mitochondrial }\end{array}$ & 2 & $0.741^{*}$ \\
\hline \multicolumn{5}{|c|}{ Fatty acid $\beta$-oxidation } \\
\hline & ACAA2 & Acetyl-CoA acyltransferase 2 & 5 & $0.826^{\star}$ \\
\hline & ACADM & Medium-chain-specific acyl-CoA dehydrogenase & 12 & $0.759^{*}$ \\
\hline & ECHS1 & Enoyl-CoA hydratase, mitochondrial & 1 & $1.398^{\star}$ \\
\hline & EHHADH & Peroxisomal bifunctional enzyme & 1 & $1.377^{\star}$ \\
\hline & $H A D H B$ & Long-chain 3-ketoacyl-CoA thiolase & 16 & $0.754^{\star}$ \\
\hline \multicolumn{5}{|c|}{ EIF2 signalling } \\
\hline & EIF4G1 & Eukaryotic translation initiation factor $4 \gamma 1$ & 5 & $1.326^{*}$ \\
\hline & FAU & $40 \mathrm{~S}$ ribosomal protein $\mathrm{S} 30$ & 1 & $1 \cdot 291^{*}$ \\
\hline & RPL7 & $60 S$ ribosomal protein $\mathrm{L} 7$ & 2 & $0.804^{*}$ \\
\hline & RPL23 & $60 S$ ribosomal protein L23 & 2 & $0.83^{*}$ \\
\hline & RPL36 & $60 S$ ribosomal protein L36 & 3 & $1 \cdot 255^{\star}$ \\
\hline & RPL27A & $60 S$ ribosomal protein L27A & 3 & $1.314^{\star}$ \\
\hline & RPS15A & 40 S ribosomal protein $S 15 A$ & 1 & $1.464^{*}$ \\
\hline & RPS27A & 40 S ribosomal protein S27A & 5 & $1.377^{\star}$ \\
\hline & RPS4X & $40 \mathrm{~S}$ ribosomal protein $\mathrm{S} 4, \mathrm{X}$ isoform & 5 & $1.446^{\star}$ \\
\hline \multicolumn{5}{|c|}{ Glycolysis I } \\
\hline & FBP2 & Fructose-1,6-bisphosphatase isozyme 2 & 6 & $1.419^{\star}$ \\
\hline & $G A P D H$ & Glyceraldehyde-3-phosphate dehydrogenase & 6 & $0.827^{\star}$ \\
\hline & PKM & Pyruvate kinase isozyme $\mathrm{M}$ & 3 & $1.269^{\star}$ \\
\hline \multicolumn{5}{|c|}{ NRF2-mediated oxidative stress response } \\
\hline & DNAJA4 & DnaJ homologue subfamily A member 4 & 3 & $0.592^{\star}$ \\
\hline & DNAJB4 & DnaJ homologue subfamily B member 4 & 5 & $0.796^{\star}$ \\
\hline & $E P H X 1$ & Epoxide hydrolase 1 & 3 & $1.353^{*}$ \\
\hline & GSTP1 & Glutathione $S$-transferase $\mathrm{P} 1$ & 6 & $1.443^{*}$ \\
\hline & HSPB8 & Heat-shock protein $\beta$-8 & 1 & $0.746^{*}$ \\
\hline & MAP2K6 & Dual specificity mitogen-activated protein kinase kinase 6 & 2 & $0.646^{*}$ \\
\hline \multicolumn{5}{|c|}{ mTOR signalling } \\
\hline & EIF4G1 & Eukaryotic translation initiation factor $4 \gamma 1$ & 5 & $1.326^{\star}$ \\
\hline & FAU & $40 S$ ribosomal protein $\mathrm{S} 30$ & 1 & $1 \cdot 291^{*}$ \\
\hline & $R P L 27 A$ & $60 S$ ribosomal protein L27A & 3 & $1.314^{\star}$ \\
\hline & RPS15A & $40 \mathrm{~S}$ ribosomal protein $\mathrm{S} 15 \mathrm{~A}$ & 1 & $1.464^{\star}$ \\
\hline & RPS4X & $40 \mathrm{~S}$ ribosomal protein $\mathrm{S} 4, \mathrm{X}$ isoform & 5 & $1.446^{\star}$ \\
\hline & EIF4G1 & Eukaryotic translation initiation factor $4 \times 1$ & 5 & $1.326^{\star}$ \\
\hline \multicolumn{5}{|c|}{ Protein ubiquitination pathway } \\
\hline & B2M & $\beta$-2-microglobulin & 1 & $0.75^{\star}$ \\
\hline & CRYAB & a-Crystallin B chain & 3 & $0.554^{\star}$ \\
\hline & DNAJB4 & DnaJ homologue subfamily B member 4 & 5 & $0.796^{\star}$ \\
\hline & HSPA1A & Heat-shock $70 \mathrm{kDa}$ protein $1 \mathrm{~A}$ & 5 & $0.712^{\star}$ \\
\hline & HSPB2 & Heat-shock protein $\beta-2$ & 5 & $0.8^{*}$ \\
\hline & HSPB6 & Heat-shock protein $\beta-6$ & 2 & $0.558^{\star}$ \\
\hline & HSPB7 & Heat-shock protein $\beta-7$ & 1 & $0.344^{\star}$ \\
\hline & HSPB8 & Heat-shock protein $\beta-8$ & 1 & $0.746^{\star}$ \\
\hline & PSMC2 & $26 S$ protease regulatory subunit 7 & 4 & $0.763^{*}$ \\
\hline & PSME1 & Proteasome activator complex subunit 1 & 3 & $0.829^{\star}$ \\
\hline
\end{tabular}

HL, high-leucine diet; NL, normal leucine diet; EIF2, eukaryotic initiation factor 2; NRF2, nuclear factor-erythroid 2-related factor 2; mTOR, mechanistic target of rapamycin.

${ }^{*} P<0.05$. 
Table 2. The concentration of AMP and ATP in longissimus dorsi muscle from normal leucine diet (NL) and high-leucine diet $(\mathrm{HL})$ groups (Mean values with their standard errors)

\begin{tabular}{lrccccc}
\hline & \multicolumn{2}{c}{$\mathrm{NL}(n$ 3) } & & \multicolumn{2}{c}{$\mathrm{HL}(n$ 3) } & \\
\cline { 2 - 3 } & Mean & SEM & & Mean & SEM & $P$ \\
\hline AMP $(\mu \mathrm{g} / \mathrm{ml})$ & 18.368 & 4.609 & & 6.411 & 0.792 & 0.043 \\
ATP $(\mu \mathrm{g} / \mathrm{ml})$ & 150.436 & 16.77 & & 85.66 & 7.073 & 0.024 \\
AMP:ATP & 0.096 & 0.008 & & 0.067 & 0.008 & 0.046 \\
\hline
\end{tabular}

the HL group in the iTRAQ data (Table 1) and Western blotting analysis (Fig. 5(d) and (e)). MAP2K6 is one of major regulators for p38 mitogen-activated protein kinase (also named as p38) activation $^{(42,43)}$, and GSTP1 is considered to be an inhibitor for c-JUN NH2-terminal protein kinase (JNK) activation ${ }^{(44)}$. These results suggest the inhibition of $\mathrm{p} 38 / \mathrm{JNK}$ pathway. In addition, MSTN is a member of the transforming growth factor- $\beta$ family that is widely distributed in muscle tissue and is regarded as a negative regulator of muscle growth ${ }^{(45)}$. We detected that the expression of MSTN is declined in LD muscle derived from the HL group (Fig. 5(f)).

\section{Discussion}

A proteome-wide analysis on weanling piglets expands our knowledge of how leucine supplementation affects skeletal muscle metabolism. To our knowledge, this is the first report of proteomic analysis that analysed the effects of dietary supplementation with leucine in weanling piglets. In the present study, the 157 differentially expressed proteins between the NL and the HL groups, altered by dietary leucine supplementation, demonstrate the changes in energy metabolism, protein synthesis and fibre-type distribution in the LD muscle of weanling piglets.

Muscles, which convert chemical energy into mechanical movement, are of critical importance as storage organs for energy, as well as for the maintenance of energy homoeostasis. Two core metabolic pathways, glycolysis and OXPHOS, are involved in ATP production for energy, whereas glycolysis is a catabolic process that converts glucose to pyruvate, which then can be completely oxidised to produce maximal amounts of ATP through the OXPHOS pathway. Besides glucose, fatty acid and amino acid also serve as energy substrates involved in mitochondrial oxidation ${ }^{(46)}$. Indeed, in skeletal muscle, the regulation of energy homoeostasis in different conditions triggers whole rearrangement of glucose and lipid metabolisms ${ }^{(47)}$, which always is accompanied by the modulation of glycolysis or OXPHOS. In this case, we identified that fourteen differentially expressed proteins in OXPHOS pathway responded to leucine supplementation, which suggests that high-level leucine suppresses the OXPHOS pathway. With this in perspective, we showed a suppressed FAO and a lower ATP content in the HL group. Moreover, compared with the NL group, the study results in the iTRAQ experiment exhibited an increased abundance of hexokinase 1 (1.246-fold) and PKM (1.269-fold) in leucine-supplemented piglets, which results in enhanced glycolytic activity. Thus, high-level leucine leads to a shift from oxidative to glycolytic metabolism in the LD muscle of weanling piglets.

Because of the alterations in fibre type distribution, skeletal muscle fibres exhibit a physiological plasticity adapting to the diverse conditions ${ }^{(48,49)}$. Of the two main fibre types in skeletal muscle, the fast type IIb fibre has less mitochondrion but higher activity of glycolytic enzymes than the other type. Lombardi et al. ${ }^{(50)}$ reported an increase in various oxidative enzymes and a decrease in glycolytic enzymes in aged gastrocnemius of rats with the increase in slow-type myosin proteins and the decrease in fast-type myosin proteins. They concluded a transition from fast-to-slow muscle fibre and a glycolytic-to-oxidative metabolic shift during skeletal muscle ageing. Moreover, chronic stimulation of $\beta 2$-adrenoceptors induces shifts from the MyHC I to the MyHC II isoform and from an oxidative to a glycolytic phenotype in rats ${ }^{(51)}$. These results indicate that the alterations in energy metabolic pathways significantly correlate with muscle fibre transitions.

Many myofibrillar proteins have been shown in the study data. Troponin T protein (TNNT), fast skeletal muscle (TNNT3, 2.126-fold) and troponin I, fast skeletal muscle (TNNI2, 1.253fold, non-significant in iTRAQ), the specific proteins in fast muscle fibres ${ }^{(52)}$, all show an increased expression in the HL group. Whereas, troponin I, slow skeletal muscle (TNNI1, $0 \cdot 68$-fold, non-significant in iTRAQ) and tropomyosin $\alpha-3$ chain (0.75-fold), which are mainly expressed in slow muscle fibres ${ }^{(53)}$, are all down-regulated by leucine supplementation. Furthermore, the fast fibre types show the lowest activity of $\mathrm{SDH}^{(54)}$. The study results show that the expression of three enzymes SDHB (0.761-fold), SDHC (0.793-fold) and SDHD ( $0 \cdot 741$-fold) are decreased in the HL group. We also detected a decreased expression of MyHC I, MyHC IIa, MyHC IIx and an increased expression of MyHC IIb in the HL group. All these results suggest that leucine supplementation increases the growth of fast-twitch muscle fibres and decrease in the slow type. Thus, the up-regulated glycolysis and down-regulated OXPHOS in the LD muscle explains that, probably, leucine supplementation yields a higher percentage of glycolytic type II fibres during postweaning time.

Previous studies have corroborated that leucine alone is sufficient to regulate the activity of the mTOR pathway ${ }^{(55)}$ and that it acts as a modulator of muscle protein synthesis ${ }^{(56,57)}$. In contrast, as a negative regulator for muscle growth, MSTN can inhibit the mTOR-mediated protein synthesis pathway ${ }^{(58)}$ and activate the protein degradation pathway ${ }^{(59,60)}$. Liu et al. ${ }^{(61)}$ reported that maternal low-protein diet could up-regulate MSTN in the skeletal muscle of weanling piglets. They also reported a decreased leucine level in blood and inhibition of mTOR pathway in the skeletal muscle of weanling piglets. The study results also found that the ratios of p-mTOR:mTOR and $\mathrm{p}-\mathrm{p} 70^{\mathrm{S} 6 \mathrm{~K}}: \mathrm{p} 70^{\mathrm{S} 6 \mathrm{~K}}$ were increased in the HL group. In addition, EIF4G1 and proteins from 60S ribosomal subunit (RPL36 and RPL27A) and 40S ribosomal subunit (FAU, RPS15A, RPS27A and RPS4X) were all up-regulated in the leucine-supplemented condition. Moreover, the ITRAQ data also showed that the proteins in the protein ubiquitination pathway (beta-2-microglobulin (B2M), alpha-crystallin B chain (CRYAB), DnaJ homolog subfamily B member 4 (DNAJB4), heat shock $70 \mathrm{kDa}$ 
(a)

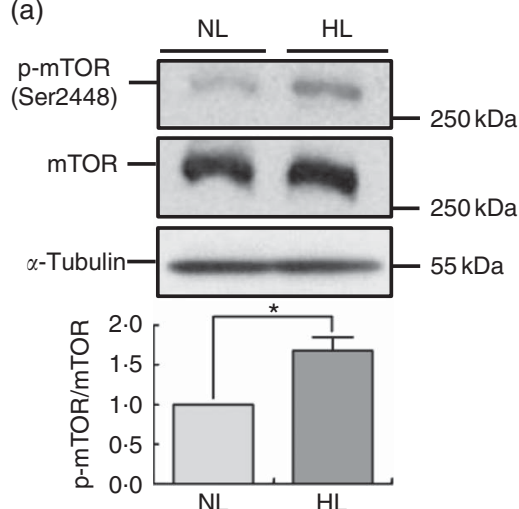

(b)
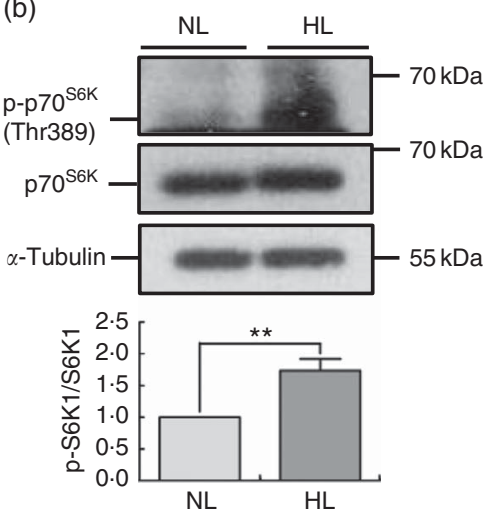

(c)
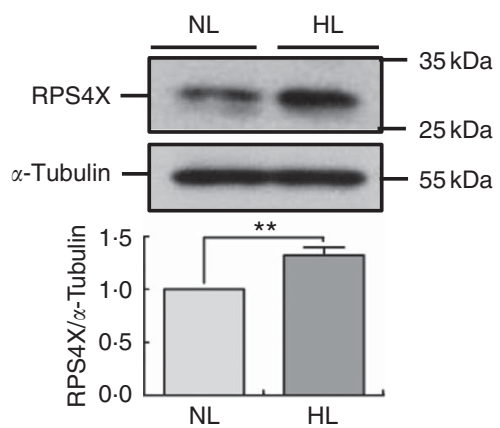

(e)
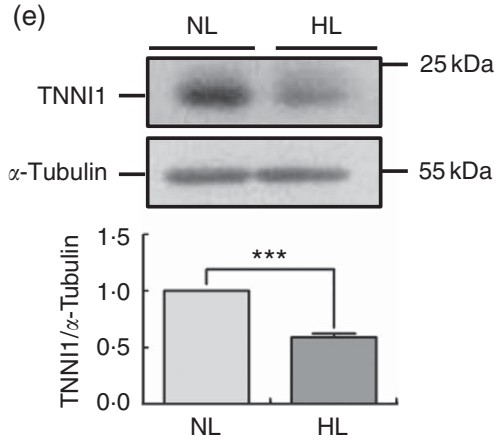

(h)

(f)

\begin{tabular}{llc}
\hline Gene symbol & \multicolumn{1}{c}{ Protein name } & Ratio (HL/NL) \\
\hline TNNT3 & Troponin T, fast skeletal muscle & $2 \cdot 126^{*}$ \\
TNNI2 & Troponin I, fast skeletal muscle & $1 \cdot 253$ \\
MYL3 & Myosin light chain 3 & 0.651 \\
TNN11 & Troponin I, slow skeletal muscle & 0.68 \\
TPM3 & Tropomyosin $\alpha$-3 chain & $0 \cdot 75^{\star}$ \\
MYH1 & Myosin-1 & $0.618^{*}$ \\
TPM2 & Tropomyosin $\beta$ chain & $2 \cdot 524^{*}$ \\
MYL9 & Myosin regulatory light polypeptide 9 & 1.372 \\
\hline
\end{tabular}
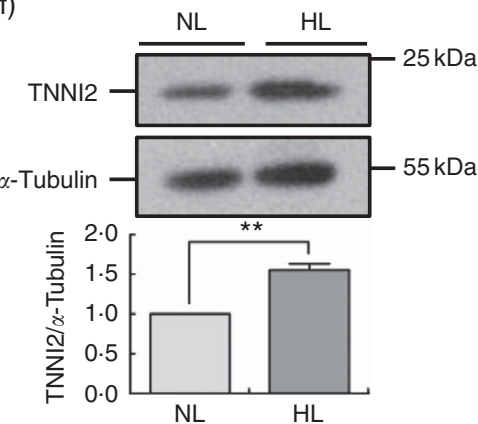

(i)

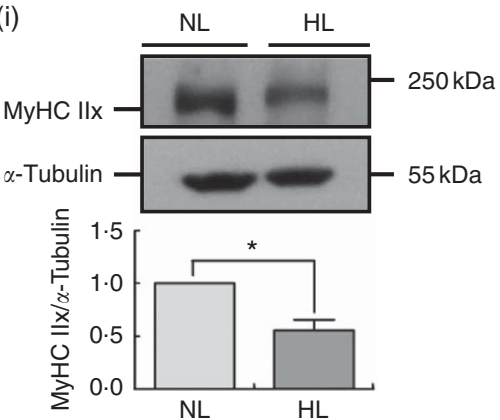

(g)
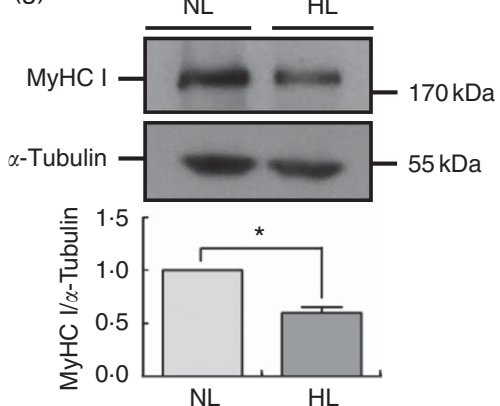

(j)

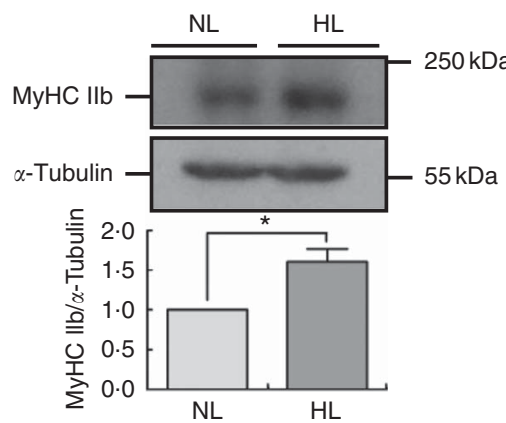

Fig. 4. Leucine supplementation promotes protein synthesis and slow-to-fast muscle fibre transitions. The expression of p-mTOR, mTOR (a), p-p70 ${ }^{\mathrm{S} 6 \mathrm{~K}}, \mathrm{p} 70^{\mathrm{S} 6 \mathrm{~K}}$ (b), RPS4X (c), TNNI1 (e), TNNI2 (f), MyHC I (g), MyHC Ila (h), MyHC Ilx (i) and MyHC Ilb (j) induced by leucine were confirmed by Western blotting analysis. (d) Myofibrillar proteins identified in high-leucine diet $(\mathrm{HL})$ group compared with normal leucine diet (NL) group. Values are means ( $n 4$ experiments) with their standard errors represented by vertical bars. ${ }^{*} P<0.05 ;{ }^{* *} P<0.01$; ${ }^{* \star \star} P<0.001$. $a$-Tubulin was detected as a loading control. HL, high-leucine diet; NL, normal leucine diet.

protein 1A (HSPA1A), heat shock protein beta-2 (HSPB2), heat shock protein beta-6 (HSPB6), heat shock protein beta-7 (HSPB7), heat shock protein beta-8 (HSPB8), 26S protease regulatory subunit 7 (PSMC2), proteasome activator complex subunit 1 (PSME1)) were all decreased in the HL group (Table 1 ). These results suggest that dietary leucine supplementation 
(a)
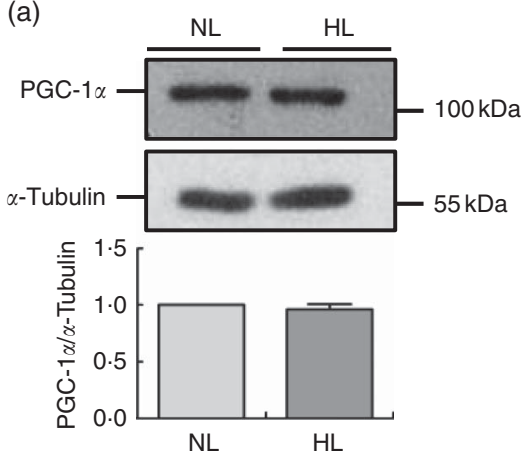

(d)

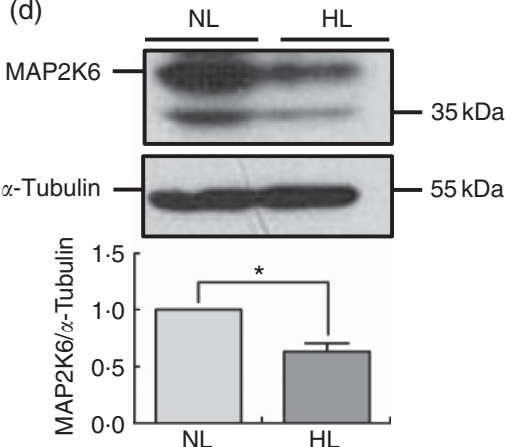

(b)
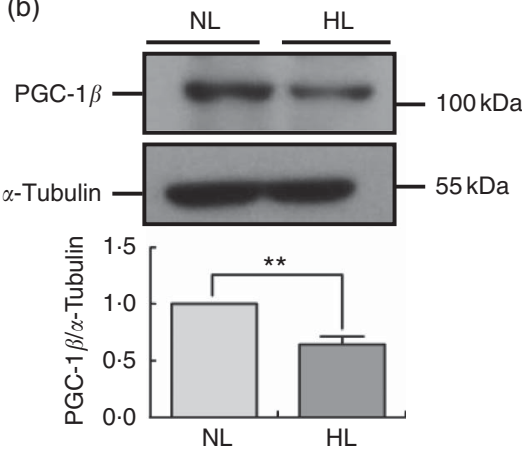

(e)

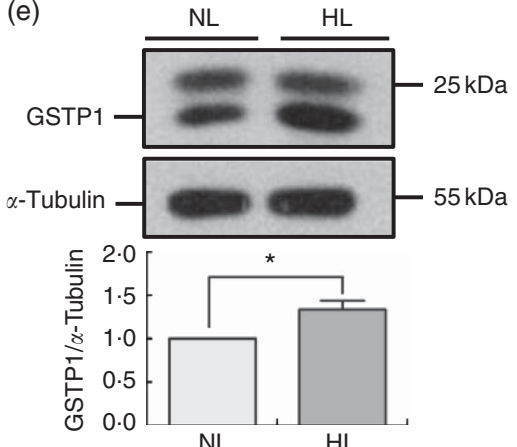

(c)

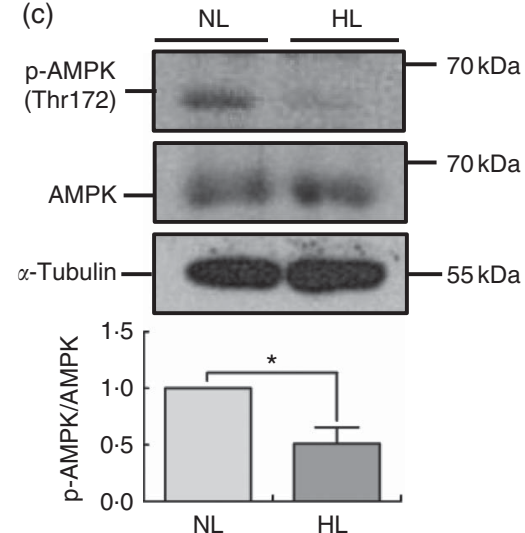

(f)

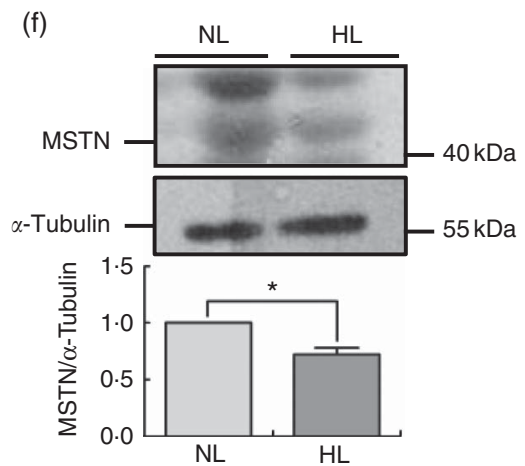

Fig. 5. Leucine supplementation decreases the activity of AMP-activated protein kinase (AMPK) and suppresses the p38/c-JUN NH2-terminal protein kinase pathway. Western blotting detected the expression of PPARy coactivator-1a (PGC-1a) (a), PPARy coactivator-1 $\beta$ (PGC-1 $\beta$ ) (b), p-AMPK, AMPK (c), MAP2K6 (d), Glutathione S-transferase P1 (GSTP1) (e) and myostatin (MSTN) (f) in high-leucine diet (HL) group compared with normal leucine diet (NL) group. Values are means ( $n 5$ experiments) with their standard errors represented by vertical bars. ${ }^{\star} P<0.05$, ${ }^{\star \star} P<0.01$. $a$-Tubulin was detected as a loading control.

promotes muscle protein synthesis, and that leucine might inhibit the function of MSTN in skeletal muscle.

Numerous studies have shown that loss of MSTN leads to an increased proportion of fast type II fibres and a reduced proportion of slow type I fibres in littermates or aged muscles ${ }^{(62,63)}$. This phenomenon suggests that the loss of MSTN might cause a transformation to a more fast-twitch phenotype in skeletal muscle. Moreover, MSTN is a secreted protein from the skeletal muscle ${ }^{(45)}$, and two receptors named activin receptor type IIB and activin receptor-like kinase (ALK4/5) initiate MSTN signalling ${ }^{(64,65)}$. MSTN can inhibit AMPK through its receptors ${ }^{(66)}$, which was supported by the finding that MSTNdeficient mice exhibit the activation of the AMPK signalling pathway $^{(67)}$. Interestingly, Das et al. ${ }^{(68)}$ showed that AMPK can stimulate the expression of MSTN. These findings suggested that there might be a negative feedback loop between AMPK and MSTN. Thus, a possible explanation for the decreased MSTN expression and phosphorylation of AMPK in our results is that leucine supplementation inhibits the activation of AMPK, thus leading to the reduced expression of MSTN. The decreased MSTN may act to protect AMPK from over-inhibition by leucine. In addition, MSTN can induce the activation of either the $\mathrm{p} 38^{(69)}$ or the JNK signalling pathway ${ }^{(70)}$ in the adult murine myoblast cell line $\mathrm{C} 2 \mathrm{C} 12$. However, Morissette et al. ${ }^{(71)}$ observed that overexpression of MSTN did not increase the phosphorylation of p38 in neonatal rat cardiomyocytes. The decreased levels of MSTN and p38/JNK observed in the HL group implies that a high level of leucine in the diet promotes a more fast-twitch phenotype in the skeletal muscle of weanling piglets, and that MSTN might have a stage-dependent effect on p38.

PGC-1 has been proved to be a master regulator for cellular energy metabolism, and a key signalling molecule for fibre-type determination $^{(72,73)}$. Several reports demonstrated that PGC-1mediated myofibre switching towards a slower and oxidative phenotype. Overexpression of PGC- $1 \alpha$ in skeletal muscle leads to the increase of slow-type fibres and the expression of OXPHOS proteins ${ }^{(74)}$. PGC- $1 \beta$ can drive the formation of oxidative type IIX fibres ${ }^{(75)}$. Although the upstream signalling pathways involved in the regulation of PGC-1 are still largely unknown, both AMPK and p38 can affect PGC- $1 \alpha$ expression and activity ${ }^{(76)}$. As reported recently, AMPK has been associated with crucial roles in fibre-type transformation and mitochondrial biogenesis, mainly relying on the function of PGC- $1 \alpha^{(77,78)}$. In addition, p38 has been shown to contribute to the induction of PGC- $1 \alpha$ expression ${ }^{(79)}$ and to directly phosphorylate PGC- $1 \alpha^{(80,81)}$. However, the interaction between AMPK, p38 and PGC- $1 \beta$ expression is rarely reported. Simultaneously, PGC-1 have been shown to robustly induce the expression of a specific transcription factor myocyte enhancer factor- $2^{(74,75)}$, which can enhance the majority of muscle-specific gene expression $^{(82)}$, and is involved in the formation of slow-twitch muscle fibres ${ }^{(83,84)}$. In this case, our results indicated that PGC- $1 \alpha$ showed no significant change, but PGC- $1 \beta$ was downregulated, after leucine supplementation. We speculated that 
the decreased expression of MSTN and the inhibition of p38 and AMPK will lead to the decreased expression and activity of PGC- $1 \beta$, but not of PGC- $1 \alpha$, which will promote the switching of slow muscle fibres towards the fast type after leucine supplementation.

In conclusion, we have performed a proteomic profiling to investigate the effects of leucine supplementation on the skeletal muscle proteome of weanling piglets. The results especially indicated that leucine supplementation may alter the energy metabolism and promote slow-to-fast transitions in the skeletal muscle of weanling piglets, which provide new insights into the regulation of energy homoeostasis as well as muscle fibre transitions through leucine. However, future studies are still needed to elucidate the underlying regulatory mechanism of specific amino acids, in particular, of leucine.

\section{Acknowledgements}

The authors gratefully acknowledge all present and past members of Yan laboratory who have contributed comments and ideas.

This work was supported by the National Natural Science Foundation of China (grant nos 31322053, 31520103915 and 31172290); the National Key Basic Research Program of China (973 Program) (grant no. 2013CB127305); the Hubei Province Distinguished Young Scholar (grant no. 2012FFA015) and the Fundamental Research Funds for the Central Universities (grant nos 2662015PY111 and 2013JQ001). No funding body had any role in the design, analysis or writing of this article.

Q. F. and X. Y. designed the study, interpreted the data and wrote the manuscript; Q. F. and B. L. performed the animal studies; Q. F., G. Y., M. S. and X. B. collected the data; Q. F., Z. W., J. H., X. L., C. C. and Z. Z. conducted the biochemical experiments and analysed the data. All authors contributed to the discussion and approved the final version of this paper.

The authors declare that there are no conflicts of interest.

\section{Supplementary material}

For supplementary material/s referred to in this article, please visit https://doi.org/10.1017/S0007114517001209

\section{References}

1. Wolfson RL, Chantranupong L, Saxton RA, et al. (2016) Sestrin2 is a leucine sensor for the mTORC1 pathway. Science 351, 43-48.

2. Sun X \& Zemel MB (2009) Leucine modulation of mitochondrial mass and oxygen consumption in skeletal muscle cells and adipocytes. Nutr Metab (Lond) 6, 26.

3. D'Antona G, Ragni M, Cardile A, et al. (2010) Branched-chain amino acid supplementation promotes survival and supports cardiac and skeletal muscle mitochondrial biogenesis in middle-aged mice. Cell Metab 12, 362-372.

4. Nishitani S, Matsumura T, Fujitani S, et al. (2002) Leucine promotes glucose uptake in skeletal muscles of rats. Biochem Biophys Res Commun 299, 693-696.

5. Nair KS, Woolf PD, Welle SL, et al. (1987) Leucine, glucose, and energy metabolism after 3 days of fasting in healthy human subjects. Am J Clin Nutr 46, 557-562.
6. Chang T \& Goldberg A (1978) Leucine inhibits oxidation of glucose and pyruvate in skeletal muscles during fasting. $J$ Biol Chem 253, 3696-3701.

7. Paul HS \& Adibi SA (1976) Assessment of effect of starvation, glucose, fatty acids and hormones on alpha-decarboxylation of leucine in skeletal muscle of rat. J Nutr 106, 1079-1088.

8. Li H, Xu M, Lee J, et al. (2012) Leucine supplementation increases SIRT1 expression and prevents mitochondrial dysfunction and metabolic disorders in high-fat diet-induced obese mice. Am J Physiol Endocrinol Metab $\mathbf{3 0 3}$, E1234-E1244.

9. Pette D \& Staron RS (2000) Myosin isoforms, muscle fiber types, and transitions. Microsc Res Tech 50, 500-509.

10. Schiaffino S \& Reggiani C (1994) Myosin isoforms in mammalian skeletal muscle. J Appl Physiol 77, 493-501.

11. Matsakas A \& Patel K (2009) Skeletal muscle fibre plasticity in response to selected environmental and physiological stimuli. Histol Histopathol 24, 611-629.

12. Davidsen PK, Gallagher IJ, Hartman JW, et al. (2011) High responders to resistance exercise training demonstrate differential regulation of skeletal muscle microRNA expression. J Appl Physiol 110, 309-317.

13. Ohlendieck K (2010) Proteomics of skeletal muscle differentiation, neuromuscular disorders and fiber aging. Expert Rev Proteomics 7, 283-296.

14. Reeds PJ, Fjeld CR \& Jahoor F (1994) Do the differences between the amino acid compositions of acute-phase and muscle proteins have a bearing on nitrogen loss in traumatic states? J Nutr 124, 906-910.

15. Anthony JC, Anthony TG, Kimball SR, et al. (2000) Orally administered leucine stimulates protein synthesis in skeletal muscle of postabsorptive rats in association with increased eIF4F formation. J Nutr 130, 139-145.

16. Vary TC (2007) Acute oral leucine administration stimulates protein synthesis during chronic sepsis through enhanced association of eukaryotic initiation factor $4 \mathrm{G}$ with eukaryotic initiation factor $4 \mathrm{E}$ in rats. $J$ Nutr 137, 2074-2079.

17. Mobley CB, Fox CD, Thompson RM, et al. (2016) Comparative effects of whey protein versus L-leucine on skeletal muscle protein synthesis and markers of ribosome biogenesis following resistance exercise. Amino Acids 48, 733-750.

18. Escobar J, Frank JW, Suryawan A, et al. (2005) Physiological rise in plasma leucine stimulates muscle protein synthesis in neonatal pigs by enhancing translation initiation factor activation. Am J Physiol Endocrinol Metab 288, E914-E921.

19. Suryawan A, Jeyapalan AS, Orellana RA, et al. (2008) Leucine stimulates protein synthesis in skeletal muscle of neonatal pigs by enhancing mTORC1 activation. Am J Physiol Endocrinol Metab 295, E868-E875.

20. Hernandez-Garcia AD, Columbus DA, Manjarin R, et al. (2016) Leucine supplementation stimulates protein synthesis and reduces degradation signal activation in muscle of newborn pigs during acute endotoxemia. Am J Physiol Endocrinol Metab 311, E791-E801.

21. Koopman R, Verdijk L, Manders RJ, et al. (2006) Co-ingestion of protein and leucine stimulates muscle protein synthesis rates to the same extent in young and elderly lean men. $A m J$ Clin Nutr 84, 623-632.

22. Bukhari SS, Phillips BE, Wilkinson DJ, et al. (2015) Intake of low-dose leucine-rich essential amino acids stimulates muscle anabolism equivalently to bolus whey protein in older women at rest and after exercise. Am J Physiol Endocrinol Metab 308, E1056-E1065.

23. Kramer IF, Verdijk LB, Hamer HM, et al. (2016) Both basal and post-prandial muscle protein synthesis rates, following the ingestion of a leucine-enriched whey protein supplement, 
are not impaired in sarcopenic older males. Clin Nutr 16, 31263-31268.

24. Stickland N, Widdowson EM \& Goldspink G (1975) Effects of severe energy and protein deficiencies on the fibres and nuclei in skeletal muscle of pigs. BrJ Nutr 34, 421-428

25. Goldspink G \& Ward P (1979) Changes in rodent muscle fibre types during post-natal growth, undernutrition and exercise. J Physiol 296, 453-469.

26. Sieck GC, Lewis MI \& Blanco C (1989) Effects of undernutrition on diaphragm fiber size, SDH activity, and fatigue resistance. J Appl Physiol 66, 2196-2205.

27. Xia Z, Cholewa J, Zhao Y, et al. (2016) Hypertrophypromoting effects of leucine supplementation and moderate intensity aerobic exercise in pre-senescent mice. Nutrients $\mathbf{8}$ E246.

28. Okumura N, Hashida-Okumura A, Kita K, et al. (2005) Proteomic analysis of slow- and fast-twitch skeletal muscles. Proteomics 5, 2896-2906

29. Le Bihan MC, Hou Y, Harris N, et al. (2006) Proteomic analysis of fast and slow muscles from normal and kyphoscoliotic mice using protein arrays, 2-DE and MS. Proteomics 6, 4646-4661.

30. Gelfi C, Vigano A, De Palma S, et al. (2006) 2-D protein maps of rat gastrocnemius and soleus muscles: a tool for muscle plasticity assessment. Proteomics 6, 321-340.

31. Gonnet F, Bouazza B, Millot GA, et al. (2008) Proteome analysis of differentiating human myoblasts by dialysisassisted two-dimensional gel electrophoresis (DAGE). Proteomics 8, 264-278.

32. Chan XC, McDermott JC \& Siu KW (2007) Identification of secreted proteins during skeletal muscle development. J Proteome Res 6, 698-710.

33. Guelfi KJ, Casey TM, Giles JJ, et al. (2006) A proteomic analysis of the acute effects of high-intensity exercise on skeletal muscle proteins in fasted rats. Clin Exp Pharmacol Physiol 33 , 952-957.

34. Almeida AM, van Harten S, Campos A, et al. (2010) The effect of weight loss on protein profiles of gastrocnemius muscle in rabbits: a study using 1D electrophoresis and peptide mass fingerprinting. J Anim Physiol Anim Nutr (Berl) 94, 174-185.

35. Hwang H, Bowen BP, Lefort $\mathrm{N}$, et al. (2010) Proteomics analysis of human skeletal muscle reveals novel abnormalities in obesity and type 2 diabetes. Diabetes 59, 33-42.

36. Gelfi C, Vigano A, Ripamonti $\mathrm{M}$, et al. (2006) The human muscle proteome in aging. J Proteome Res 5, 1344-1353.

37. Gannon J, Staunton L, O'Connell K, et al. (2008) Phosphoproteomic analysis of aged skeletal muscle. Int J Mol Med $\mathbf{2 2}$, $33-42$.

38. Wang X, Ou D, Yin J, et al. (2009) Proteomic analysis reveals altered expression of proteins related to glutathione metabolism and apoptosis in the small intestine of zinc oxidesupplemented piglets. Amino Acids 37, 209-218.

39. Goichon A, Chan P, Lecleire S, et al. (2013) An enteral leucine supply modulates human duodenal mucosal proteome and decreases the expression of enzymes involved in fatty acid beta-oxidation. J Proteomics 78, 535-544.

40. Oyedotun KS \& Lemire BD (2004) The quaternary structure of the Saccharomyces cerevisiae succinate dehydrogenase homology modeling, cofactor docking, and molecular dynamics simulation studies. J Biol Chem 279, 9424-9431.

41. Hardie DG, Ross FA \& Hawley SA (2012) AMPK: a nutrient and energy sensor that maintains energy homeostasis. Nat Rev Mol Cell Biol 13, 251-262.

42. Deacon K \& Blank JL (1999) MEK kinase 3 directly activates MKK6 and MKK7, specific activators of the p38 and c-Jun NH2-terminal kinases. J Biol Chem 274, 16604-16610.
43. Enslen H, Raingeaud J \& Davis RJ (1998) Selective activation of p38 mitogen-activated protein (MAP) kinase isoforms by the MAP kinase kinases MKK3 and MKK6. J Biol Chem 273, $1741-1748$

44. Hayes JD \& Pulford DJ (1995) The glutathione S-transferase supergene family: regulation of GST and the contribution of the isoenzymes to cancer chemoprotection and drug resistance. Crit Rev Biochem Mol Biol 30, 445-600.

45. McPherron AC, Lawler AM \& Lee S-J (1997) Regulation of skeletal muscle mass in mice by a new TGF-p superfamily member. Nature $\mathbf{3 8 7}, 83-90$.

46. Newgard CB (2012) Interplay between lipids and branchedchain amino acids in development of insulin resistance. Cell Metab 15, 606-614.

47. Gerhart-Hines Z, Rodgers JT, Bare O, et al. (2007) Metabolic control of muscle mitochondrial function and fatty acid oxidation through SIRT1/PGC-1 $\alpha$. EMBO J 26, 1913-1923.

48. Fluck M \& Hoppeler H (2003) Molecular basis of skeletal muscle plasticity - from gene to form and function. Rev Physiol Biochem Pharmacol 146, 159-216.

49. Spangenburg EE \& Booth FW (2003) Molecular regulation of individual skeletal muscle fibre types. Acta Physiol Scand 178, 413-424.

50. Lombardi A, Silvestri E, Cioffi F, et al. (2009) Defining the transcriptomic and proteomic profiles of rat ageing skeletal muscle by the use of a cDNA array, 2D- and Blue native-PAGE approach. J Proteomics 72, 708-721.

51. Ohnuki Y, Umeki D, Cai W, et al. (2013) Role of masseter muscle $\beta_{2}$-adrenergic signaling in regulation of muscle activity, myosin heavy chain transition, and hypertrophy. J Pharmacol Sci 123, 36-46.

52. Muroya S, Nakajima I \& Chikuni K (2003) Amino acid sequences of multiple fast and slow troponin $\mathrm{T}$ isoforms expressed in adult bovine skeletal muscles. J Anim Sci 81, 1185-1192.

53. Perry SV (2001) Vertebrate tropomyosin: distribution, properties and function. J Muscle Res Cell Motil 22, 5-49.

54. Burke RE, Levine DN \& Zajac FE, 3rd (1971) Mammalian motor units: physiological-histochemical correlation in three types in cat gastrocnemius. Science 174, 709-712.

55. Hara K, Yonezawa K, Weng Q-P, et al. (1998) Amino acid sufficiency and mTOR regulate p70 S6 kinase and eIF-4E BP1 through a common effector mechanism. J Biol Chem 273 , 14484-14494.

56. Patti M-E, Brambilla E, Luzi L, et al. (1998) Bidirectional modulation of insulin action by amino acids. J Clin Invest $\mathbf{1 0 1}$, 1519-1529.

57. Anthony JC, Anthony TG, Kimball SR, et al. (2001) Signaling pathways involved in translational control of protein synthesis in skeletal muscle by leucine. J Nutr 131, 856S-860S.

58. Elliott B, Renshaw D, Getting S, et al. (2012) The central role of myostatin in skeletal muscle and whole body homeostasis. Acta Physiol (Oxf) 205, 324-340.

59. Mendias CL, Kayupov E, Bradley JR, et al. (2011) Decreased specific force and power production of muscle fibers from myostatin-deficient mice are associated with a suppression of protein degradation. J Appl Physiol (1985) 111, 185-191.

60. Lokireddy S, McFarlane C, Ge X, et al. (2011) Myostatin induces degradation of sarcomeric proteins through a Smad3 signaling mechanism during skeletal muscle wasting. Mol Endocrinol 25, 1936-1949.

61. Liu X, Pan S, Li X, et al. (2015) Maternal low-protein diet affects myostatin signaling and protein synthesis in skeletal muscle of offspring piglets at weaning stage. Eur J Nutr $\mathbf{5 4}$, 971-979. 
62. Siriett V, Platt L, Salerno MS, et al. (2006) Prolonged absence of myostatin reduces sarcopenia. J Cell Physiol 209, 866-873.

63. Jackson MF, Luong D, Vang DD, et al. (2012) The aging myostatin null phenotype: reduced adiposity, cardiac hypertrophy, enhanced cardiac stress response, and sexual dimorphism. J Endocrinol 213, 263-275.

64. Lee SJ \& McPherron AC (2001) Regulation of myostatin activity and muscle growth. Proc Natl Acad Sci U S A 98, 9306-9311.

65. Rebbapragada A, Benchabane H, Wrana JL, et al. (2003) Myostatin signals through a transforming growth factor beta-like signaling pathway to block adipogenesis. Mol Cell Biol 23, 7230-7242.

66. Biesemann N, Mendler L, Wietelmann A, et al. (2014) Myostatin regulates energy homeostasis in the heart and prevents heart failure. Circ Res 115, 296-310.

67. Zhang C, McFarlane C, Lokireddy S, et al. (2011) Myostatindeficient mice exhibit reduced insulin resistance through activating the AMP-activated protein kinase signalling pathway. Diabetologia 54, 1491-1501.

68. Das AK, Yang QY, Fu X, et al. (2012) AMP-activated protein kinase stimulates myostatin expression in $\mathrm{C} 2 \mathrm{C} 12$ cells. Biochem Biophys Res Commun 427, 36-40.

69. Philip B, Lu Z \& Gao Y (2005) Regulation of GDF-8 signaling by the p38 MAPK. Cell Signal 17, 365-375.

70. Huang Z, Chen D, Zhang K, et al. (2007) Regulation of myostatin signaling by c-Jun $\mathrm{N}$-terminal kinase in C2C12 cells. Cell Signal 19, 2286-2295.

71. Morissette MR, Cook SA, Foo S, et al. (2006) Myostatin regulates cardiomyocyte growth through modulation of Akt signaling. Circ Res 99, 15-24.

72. Lin JD, Handschin C \& Spiegelman BM (2005) Metabolic control through the PGC-1 family of transcription coactivators. Cell Metab 1, 361-370.

73. Finck BN \& Kelly DP (2006) PGC-1 coactivators: inducible regulators of energy metabolism in health and disease. J Clin Invest 116, 615-622.
74. Lin J, Wu H, Tarr PT, et al. (2002) Transcriptional co-activator PGC-1 alpha drives the formation of slow-twitch muscle fibres. Nature $\mathbf{4 1 8}, 797-801$.

75. Arany Z, Lebrasseur N, Morris C, et al. (2007) The transcriptional coactivator PGC-1 beta drives the formation of oxidative type IIX fibers in skeletal muscle. Cell Metab 5, 35-46.

76. Arany Z (2008) PGC-1 coactivators and skeletal muscle adaptations in health and disease. Curr Opin Genet Dev 18, 426-434.

77. Zong HH, Ren JM, Young LH, et al. (2002) AMP kinase is required for mitochondrial biogenesis in skeletal muscle in response to chronic energy deprivation. Proc Natl Acad Sci U S A 99, 15983-15987.

78. Roeckl KS, Hirshman MF, Brandauer J, et al. (2007) Skeletal muscle adaptation to exercise training: AMP-activated protein kinase mediates muscle fiber type shift. Diabetes 56, 2062-2069.

79. Akimoto T, Pohnert SC, Li P, et al. (2005) Exercise stimulates Pgc-1alpha transcription in skeletal muscle through activation of the p38 MAPK pathway. $J$ Biol Chem 280, 19587-19593.

80. Fan M, Rhee J, St-Pierre J, et al. (2004) Suppression of mitochondrial respiration through recruitment of p160 myb binding protein to PGC-1 alpha: modulation by p38 MAPK. Genes Dev 18, 278-289.

81. Puigserver P, Rhee J, Lin J, et al. (2001) Cytokine stimulation of energy expenditure through p38 MAP kinase activation of PPARgamma coactivator-1. Mol Cell 8, 971-982.

82. McKinsey TA, Zhang CL \& Olson EN (2002) MEF2: a calciumdependent regulator of cell division, differentiation and death. Trends Biochem Sci 27, 40-47.

83. Esser K, Nelson T, Lupa-Kimball V, et al. (1999) The CACC box and myocyte enhancer factor- 2 sites within the myosin light chain 2 slow promoter cooperate in regulating nervespecific transcription in skeletal muscle. J Biol Chem 274, 12095-12102.

84. Chin ER, Olson EN, Richardson JA, et al. (1998) A calcineurindependent transcriptional pathway controls skeletal muscle fiber type. Genes Dev 12, 2499-2509. 